\title{
PRESENCIA DEL VIRUS DE LA ENFERMEDAD DE NEWCASTLE EN AVES SILVESTRES DE UNA LAGUNA ALBUFERA CERCANA A LIMA
}

\author{
Presence of Newcastle Disease Virus in Wild Birds of a Coastal \\ Wetland Nearby Lima
}

\author{
Katrin Ventocilla W. ${ }^{1}$, Eliana Icochea D'A. ${ }^{1,2}$, Rosa Gonzales V. ${ }^{1}$, \\ Armando González Z. ${ }^{3}$
}

\section{Resumen}

\begin{abstract}
El presente estudio evaluó la presencia del virus de la Enfermedad de Newcastle en heces de aves silvestres que habitan la laguna albufera "El Paraíso", ubicada en el distrito de Huacho, Lima. Se recolectaron 942 muestras de heces frescas de diversas especies aviares y se realizó el aislamiento viral mediante la inoculación en huevos embrionados de pollo SPF de 10 días de edad. Se aislaron 4 cepas de Paramixovirus-1 (APMV-1), aparentemente de tipo lentogénico, demostrando que dichas aves estuvieron eliminando este virus. El presente estudio constituiría el primer reporte de aislamiento de APMV-1 en heces de aves silvestres aparentemente sanas en el Perú.
\end{abstract}

Palabras clave: Paramixovirus Aviar Tipo I, aves silvestres, Newcastle

\section{Abstract}

The present study evaluated the presence of the Newcastle Disease Virus in feces of wild birds inhabiting "El Paraiso" coastal wetland, located in the district of Huacho, Lima. Fresh fecal samples were collected from 942 wild birds of various species. The viral isolation was carried out by inoculating 10-day-old SPF embryonated eggs. Four isolates of Paramixovirus-1 (APMV-1), apparently the lentogenic type were obtained, showing that these birds were shedding the virus. This study represents the first in isolating APMV-1 in faeces from apparently healthy wild birds in Peru.

Key words : Avian Paramixovirus Type I (APMV-1), wild birds, Newcastle

\footnotetext{
${ }^{1}$ Laboratorio de Patología Aviar, ${ }^{3}$ Laboratorio de Medicina Veterinaria Preventiva, Facultad de Medicina Veterinaria, Universidad Nacional Mayor de San Marcos, Lima

${ }^{2}$ E-mail: eliana.icochea@gmail.com
} 


\section{INTRODUCCIÓN}

El virus de la Enfermedad de Newcastle (vENC) es uno de los patógenos de mayor importancia social y económica en la industria avícola debido a su elevada morbilidad y mortalidad. Presenta un amplio rango de hospedadores y afecta a más de 240 especies aviares (Kaleta y Baldauf, 1988; Báez, 1994; King, 1999). La Organización de la Salud Animal (OIE) ha establecido que la Enfermedad de Newcastle (ENC) representa uno de los mayores riesgos para el intercambio comercial internacional en la industria avícola, siendo de notificación obligatoria a este organismo (Martins, 2003).

El vENC pertenece a la subfamilia Paramixovirinae y al género Avulavirus (Carter et al., 2005; ICTV, 2005) y tiene como principales propiedades biológicas la actividad neuraminidasa, fusión celular, hemólisis y la actividad hemaglutinante (Baez, 1994; King, 1999). Existen nueve serotipos del paramixovirus aviar (PMVA), correspondiendo el PMVA-1 a la ENC. Las cepas del virus pertenecen a un mismo serotipo, pues no presentan variabilidad antigénica; sin embargo, presentan variabilidad en su patogenicidad, siendo clasificados de acuerdo a este criterio en Virus Velogénico Viscerotrópico, Virus Velogénico Neurotrópico, Virus Mesogénico, Virus Lentogénico y Virus Asintomático (Rojo, 1991; Alexander, 2003).

El vENC posee el rango más amplio de hospederos dentro de los nueve serotipos de Paramixovirus aviares (Flamer, 1999). Se han reportado infecciones en Anseriformes, Columbiformes, Psittaciformes, Passeriformes, Falconiformes, Cuculiformes, Strigiformes, Sphenisciformes, Gruiformes, Piciformes, Phasianidae, Struthioniformes y Pelicaniformes (Ritchie y Carter, 1995); sin embargo, el curso clínico de la enfermedad varía ampliamente entre ellas (Brugh y Beard, 1983; Fowler, 1993; Gerlach, 1994). Asimismo, se han reportado infecciones persisten- tes en aves de vida silvestre (Anseriformes, Psittaciformes, Strigiformes y Passeriformes), indicando su participación en la diseminación del virus (Ritchie y Carter, 1995).

La transmisión y diseminación del virus se produce por el contacto directo entre aves afectadas y aves susceptibles. Las aves afectadas eliminan el virus a través de los aerosoles y secreciones corporales, especialmente por las heces (King, 1999), las cuales son la principal fuente de diseminación de cepas entéricas avirulentas (Icochea, 2007).

La ENC es prevalente en el Perú, principalmente en aves de riña y de traspatio. Asimismo, las aves silvestres pueden ser portadoras del vENC y, de esa forma, ser una fuente diseminadora del virus hacia aves de producción. Debido a la gran cantidad de aves silvestres que habitan cerca de granjas avícolas, crianzas de aves de riña y casera, se desarrolló el presente estudio para determinar la posible presencia del vENC en aves silvestres de una laguna en el norte de Lima, zona de gran desarrollo avícola.

\section{Materiales y Métodos}

Se trabajó con muestras de heces de aves silvestres recolectadas en la laguna albufera "El Paraíso", ubicada en el distrito de Huacho, provincia de Huaura, Lima, durante el 2008. Se identificó las especies de aves a través de observación visual a una distancia prudencial, para no afectar sus actividades. Las muestras se tomaron de colonias de aves formadas por una sola especie para facilitar la identificación de la especie de procedencia.

Se realizaron visitas al humedal durante 3 periodos (mayo-junio de 2007, noviembrediciembre de 2007, mayo-abril de 2008). Cada periodo constó de 6 visitas en las cuales, se recolectaron 10 muestras de heces por especie aviar y un total de cinco especies por muestreo. Las muestras eran heces frescas, libres de arena o tierra, colectadas con hisopos 
estériles y se transportaron en viales con medio de cultivo celular (RPMI) enriquecido al $5 \%$ con suero fetal bovino.

El aislamiento viral se llevó a cabo en el Laboratorio de Patología Aviar de la Facultad de Medicina Veterinaria de la Universidad Nacional Mayor de San Marcos, Lima, mediante la inoculación de huevos embrionados de pollo SPF de 10 días de edad, vía cavidad alantoidea. Los embriones fueron incubados por 7 días, luego de los cuales se procedía a la evaluación del fluido alantoideo para determinar la presencia de agentes hemoaglutinantes. En toda muestra positiva a la prueba de hemaglutinación (HA), la presencia del vENC fue reconfirmada mediante la prueba de inhibición de la hemaglutinación (HI) usando un antisuero monoclonal contra el vENC y la prueba de inmunoensayo cromatográfico para detectar anticuerpos contra influenza aviar (prueba rápida “Antigen Rapid NDV Ag Test Kit").

El tamaño muestral se calculó a través de una distribución binomial donde la prevalencia crítica fue de 0.01 y la probabilidad de cero éxitos fue de 0.05 , resultando una $\mathrm{n}$ de 298. Sin embargo, para el presente estudio se tomaron 942 muestras.

\section{Resultados y Discusión}

En el Cuadro 1 se presentan los resultados del aislamiento viral realizado en las diversas especies aviares. El AMPV-1 se aisló en 4 de las 942 muestras inoculadas en los huevos embrionados SPF, sin que haya causado muerte embrionaria. Las muestras positivas provinieron de las especies Ardea alba (1/163), Larus pipixcan (1/105) y Oxyura ferruginea (2/115). La prevalencia media según la simulación beta fue de $0.41 \%$ con un intervalo de confianza de 0.12 a $0.93 \%$ (Fig. 1).

Existen varios estudios en aves silvestres basados en determinar la presencia de anticuerpos contra el vENC; sin embargo, se dispone de muy pocos estudios sobre aislamiento viral, ya que, aparentemente, el aislamiento del vENC en aves silvestres no es fácil debido a la necesitad de usar muestras frescas, así como a las complicaciones para su almacenamiento y transporte. Asimismo, se le suma la baja tasa de infección de las aves, ya que generalmente no se manifiestan signos clínicos en estas aves.

Severino (2007) aisló el vENC (paramixovirus aviar) en especies silvestres de la costa brasilera, sugiriendo que aves migratorias infectadas pueden transmitir el virus a especies residentes, y estas a su vez, podrían contaminar a las aves domésticas. Asimismo, en ese estudio se aislaron dos cepas patogénicas en Himantopus mexicanus y Sterna hirndo. En otro estudio similar, se aisló el AMPV-1 en 3 de 298 muestras de heces de aves de la playa y lagunas de Puerto Viejo, Lima. En esta área, las aves no manifestaron signos clínicos y se supone que el virus aislado fue de patogenicidad baja, ya que no ocurrió muerte embrionaria tras la inoculación (Icochea, 2007).

Como se puede observar, la presencia del APMV-1 en aves silvestres está bien documentada, resaltando el hecho que casi todas las cepas aisladas son lentogénicas. No obstante, uno de los pocos aislamientos de cepas patogénicas se realizó en los brotes ocurridos en Canadá en 1975 y 1990, donde se observó alta mortalidad y signos neurológicos en cormoranes (Heckert, 1996). Hasta 1990, la ENC raramente había sido reportada como causa de muerte en aves silvestres, hecho que cambió luego del verano de 1990 y 1992, en que se produjeron los brotes que causaron la muerte de gran cantidad de cormoranes, pelicanos y gaviotas en Canadá y Estados Unidos (Glaser et al., 1999). Brotes recientes de ENC en aves silvestres son muy raros. Allison et al. (2005) reportó una mortalidad relacionada con esta enfermedad en aves cormoranes jóvenes en Norte América. 
Cuadro 1. Aislamiento del Paramixovirus Aviar Tipo I en muestras de heces de aves silvestres de la laguna albufera "El Paraíso", Huacho, Lima

\begin{tabular}{lccc}
\hline Especie de ave silvestre & $\begin{array}{c}\text { Muestras } \\
(\mathrm{n})\end{array}$ & $\begin{array}{c}\text { "Pools" } \\
(\mathrm{n})\end{array}$ & $\begin{array}{c}\text { APMV-1 } \\
(\mathrm{n})\end{array}$ \\
\hline Phalacrocorax sp & 181 & 11 & - \\
Brasilianus sp & 75 & 7 & - \\
Pelecanus thagus & 40 & 4 & - \\
Calidris alba & 20 & 2 & - \\
Calidris mauri & 84 & 9 & - \\
Larus dominicanus & 30 & 3 & - \\
Larus cirrocephalus & 10 & 1 & - \\
Numenius phaeopus & 115 & 12 & 2 \\
Oxyura ferruginea & 163 & 16 & 1 \\
Ardea alba & 30 & 3 & - \\
Sterna elegans & 10 & 1 & - \\
Larus belcheri & 39 & 5 & - \\
Plegadis ridgwayi & 10 & 1 & - \\
Fulica ardesiaca & & & \\
Charadrius emipalmatus & 20 & 2 & - \\
Semipalmatus sp & 10 & 1 & - \\
Larus melanocephalus & 105 & 11 & 1 \\
Larus pipixcan & 942 & 90 & 4 \\
\hline Total & & & \\
\hline
\end{tabular}

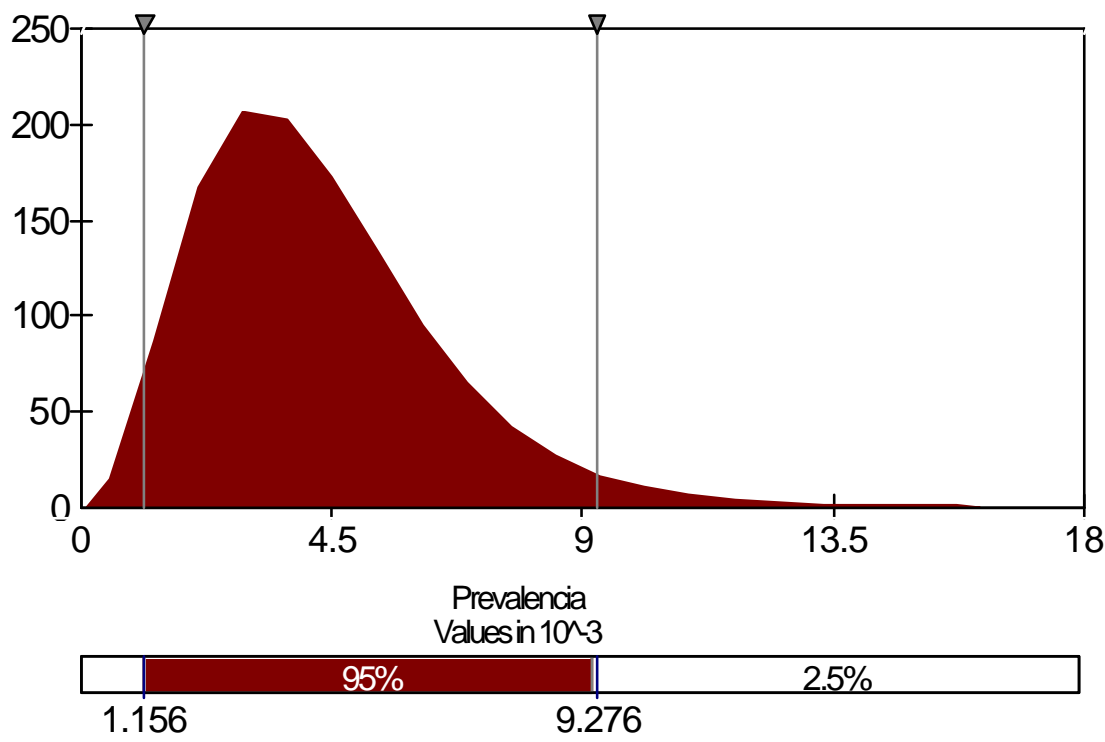

Figura 1. Distribución de la probabilidad de la prevalencia de APMV-1 en la laguna albufera "El Paraíso", con intervalos de confianza del 95\%. 
El presente estudio constituiría el primer aislamiento en heces de aves silvestres aparentemente sanas. La presencia del AMPV1 en aves silvestres que habitan la laguna albufera "El Paraíso" pone de manifiesto la importancia de un sistema de bioseguridad en las producciones avícolas cercanas.

\section{Conclusiones}

? Se aislaron 4/942 cepas de APMV-1, aparentemente de tipo lentogénico, en las heces colectadas de aves silvestres en la zona de la laguna albufera "El Paraíso".

? La prevalencia estimada fue de $0.41 \%$ con un intervalo de confianza de 0.12 a $0.93 \%$. Dicha prevalencia es muy baja para considerar a estas aves como una fuente de infección para las aves domésticas.

\section{Literatura Citada}

1. Allison AB, Gottenker NL, Stallknecht DE. 2005. Wintering of neurotropic velogenic Newcastle disease virus and West Nile virus in double crested Cormarants (phalacrocorax auritus) from the Florida Keys. Avian Dis 49: 292297.

2. Alexander D. 2003. Newcastle and other avian paramixoviridae infections. In: Saif YM, Barnes HK, Glisson JR, Fadly AM, McDougald LR, Swayne DE (eds). Diseases of Poultry. Ch. 20. 12 ed. Iowa: Iowa State University. p 75100.

3. Baez J. 1994. Enfermedad de Newcastle. En: Patología de las aves. Cap 2. México DF: Ed Trillas. p 14-18.

4. Brugh M, Beard CW. 1983. Atypical disease produced in chickens by Newcastle Disease virus isolated form exotic birds. Avian Dis 28: 482-488.

5. Carter GR, Wise DJ, Flores EF. 2005. Paramixoviridae. In: A concise review of veterinary virology. International
Veterinary Information Services, Ithaca, Nueva York (www.ivis.org) Document $\mathrm{N}^{\circ} \mathrm{A} 3423.1105$.

6. Flamer K. 1999. Zoonoses acquired from birds. In: Fowler ME, Miller RE (eds). Zoo and Wild Animal Medicine: current therapy. $4^{\text {h }}$ ed. Pennsylvania, USA: WB Saunders. p 152-154.

7. Fowler ME. 1993. Zoo and wild animal medicine current therapy. $3^{\text {rd }} \mathrm{ed}$. Pennsylvania, USA: WB Saunders. $244 \mathrm{p}$.

8. Gerlach H. 1994. Disease etiologies: Viruses. In: Ritchie BW, Harrison GJ, Harrison R (eds). Avian medicine: principles and applications. Florida: Wingers Publ. p 920-929.

9. Glaser LC, Barker IK, Weseloh DV, Ludwig J, Windingstad RM, Key DW, Bollinger TK. 1999. The 1992 epizootic of Newcastle disease in double-crested cormorants in North America. J Wildlife Dis 35: 319-330.

10. Heckert RA, Collins MS, Manvell RJ, Strong I, Pearson JE, Alexander DJ. 1996. Comparison of Newcastle Disease virus isolated from cormorants in Canada and the USA in 1975, 1990 and 1992. Can J Vet Res 60: 50-54.

11. Icochea D. 2007. Relación entre aves silvestres y la enfermedad de Newcastle en el Perú. Tesis de Magíster. Lima: Facultad de Medicina Veterinaria, Univ Nacional Mayor de San Marcos. 71 p.

12. [ICTV] International Committee of Taxonomy of Viruses. 2005. Reports of the International Committee of Taxonomy of Viruses. [Internet]. Available in: http:// www.ictvdb.iacr.ac.uk

13. Kaleta EF, Baldauf C. 1988. Newcastle disease in free-living and pet birds. In: Alexander DJ (ed). Newcastle Disease. Boston, USA: Kluwer Academic Pub. p 197-246.

14. King D. 1999. Enfermedad de Newcastle. En: XVI Congreso Latinoamericano de Avicultura. Lima, Perú.

15. Martins P. 2003. Impacto económico de las enfermedades avícolas de la lista "A" de la OIE. En: Seminario Internacional Influenza Aviar y Enfermedad de 
Newcastle: "Estandarización de criterios sanitarios para el comercio". Lima: Grupo Interamericano de Coordinación en Salud Animal.

16. Ritchie B, Carter K. 1995. Avian viruses: function and control. Florida: Wingers. $525 \mathrm{p}$.
17. Rojo ME. 1991. Enfermedades de las aves. $2^{\mathrm{a}}$ ed. México: Trillas. $344 \mathrm{p}$.

18. Severino J. 2007. Migracao de aves: Influenza aviaria e a doenca de Newcastle no Brasil. En: Conferencia APINCO 2007 de Ciencia e Tecnologia Avicola. Porto Alegre, Brasil. 